\title{
Satisfação Conjugal: Revisão Integrativa da Literatura Científica Nacional ${ }^{1}$
}

\author{
Fabio Scorsolini-Comin ${ }^{2}$ \\ Universidade Federal do Triângulo Mineiro \\ Manoel Antônio dos Santos \\ Universidade de São Paulo (Ribeirão Preto)
}

\begin{abstract}
RESUMO - Este estudo tem por objetivo apresentar uma revisão integrativa acerca do construto 'satisfação conjugal'. A partir das bases de dados LILACS e SciELO (1970-2008), foram recuperados e analisados 10 trabalhos. A maioria trata da definição de conceitos (e.g., ajustamento, qualidade) relacionados ao tema. Encontram-se investigações em diferentes contextos de casais e de construção de instrumentos de mensuração. Os estudos revelam que o relacionamento conjugal está positivamente associado à saúde e à qualidade de vida, principalmente nos anos de maturidade e velhice, embora seja apontada a necessidade de um maior número de estudos sistemáticos no contexto brasileiro.
\end{abstract}

Palavras-chave: satisfação conjugal; relações conjugais; psicologia positiva.

\section{Marital Satisfaction: Integrative Review of National Scientific Literature}

\begin{abstract}
This study aims to present an integrative review of the construct 'marital satisfaction'. Ten studies, recovered from LILACS and SciELO databases (1970-2008), were analyzed. Most of the studies deal with the definition of concepts (e.g., adjustment, quality) related to the subject. There are investigations in different couple contexts and of construction of measurement instruments. The studies show that the marital relationship is positively associated with health and quality of life, especially in the maturity and oldness. Further systematic studies in the Brazilian context are needed.
\end{abstract}

Keywords: marital satisfaction; marital relationship; positive psychology.

Segundo Machado (2007), a necessidade de se estar com o outro é algo típico do ser humano. Tal necessidade começa no nascimento, nas primeiras relações com as figuras de referência. Assim, somos constituídos pelos relacionamentos que estabelecemos, motivo pelo qual é muito importante investigarmos como se dão esses vínculos. De acordo com as reflexões de Lipovetsky (2006/2007), a nova ordem cultural na contemporaneidade valoriza os laços emocionais e sentimentais, as trocas íntimas entre as pessoas e a proximidade comunicacional com o outro. Perlin (2006) afirma que, a despeito de, na modernidade, o casamento ter sido locus da vida comum e ponto de partida para a formação da família, atualmente há um estágio no qual as relações são marcadas por um aprofundamento do individualismo, que estimula a instabilidade do relacionamento íntimo e leva a constantes reformulações dos projetos conjugais; esses fenômenos contemporâneos evidenciam a necessidade de aceitação das heterogeneidades, das descontinuidades e efemeridades das relações. Féres-Carneiro (1998) considera

1 Os autores agradecem ao apoio financeiro recebido da Fundação de Amparo à Pesquisa do Estado de São Paulo (Processo FAPESP 2007/52584-5) para a realização desta pesquisa.

2 Endereço para correspondência: Departamento de Psicologia do Desenvolvimento, da Educação e do Trabalho, Universidade Federal do Triângulo Mineiro. Avenida Getúlio Guaritá, 159, $3^{\circ}$ andar, Abadia. Uberaba, MG. CEP: 38025-440.E-mail: scorsolini@psicologia.uftm. edu.br. o casamento contemporâneo representante de uma relação de intensa significação na vida das pessoas, envolvendo alto grau de intimidade e um grande investimento afetivo. Encontrar alguém para compartilhar a vida e ter filhos parece ser um busca incansável, e o casamento ainda configura um rito de passagem muito significativo em várias sociedades (Scorsolini-Comin \& Santos, 2008).

Segundo dados recentes do Instituto Brasileiro de Geografia e Estatística - IBGE (2007), em 2006 o total de casamentos no Brasil foi de 889.828 , número $6,5 \%$ maior do que o apurado no ano anterior, confirmando a tendência de crescimento que vem sendo registrada no país desde 2002. Segundo o documento de divulgação da pesquisa, o aumento pode estar relacionado à legalização de uniões consensuais. Além disso, os pesquisadores atribuem a expansão também à realização de casamentos coletivos, que têm o atrativo da redução de custos. De acordo com os autores da pesquisa, a questão dos custos é responsável também pela realização do maior número de casamentos no mês de dezembro, quando o pagamento do $13^{\circ}$ salário e outros benefícios aumentam a disponibilidade financeira. A pesquisa mostra que, em 2006, do total de casamentos realizados, $85,2 \%$ ocorreram entre solteiros. No entanto, houve declínio nesse tipo de casamento, que em 1996 representava $90,9 \%$ do total. Por outro lado, é crescente a proporção de casamentos de indivíduos divorciados com cônjuges solteiros. O porcentual de homens divorciados 
que casaram com mulheres solteiras passou de $4,2 \%$ do total de casamentos realizados no país em 1996 para $6,5 \%$ em 2006. Também houve aumento do porcentual de casamentos entre cônjuges divorciados, de 0,9\% em 1996 para 2,2\% em 2006.

Para Dessen e Braz (2005), o relacionamento marital tem sido apontado, recentemente, como um fator preponderante para a qualidade de vida das famílias, particularmente no que tange às relações que pais e mães mantêm com suas crianças. $\mathrm{O}$ relacionamento conjugal está associado à saúde e qualidade de vida, principalmente nos anos de maturidade e velhice, embora o fato de um casamento durar não necessariamente signifique que o mesmo seja satisfatório para os cônjuges. De qualquer modo, segundo Costa (2005), a conjugalidade é fundamental para o bem-estar psicológico e social dos indivíduos. De acordo com Perlin (2006), casamento e satisfação se tornaram, ao longo da história do ocidente, estreitamente interdependentes. O casamento, dentro de nossa estrutura política e econômica, tem sido definido como uma resultante social que satisfaz necessidades básicas do indivíduo. Dias (2000) afirma que o casamento contemporâneo tem algumas características determinantes, entre as quais está a busca da felicidade, da satisfação e do amor. Ainda segundo Perlin (2006), “o desejo intenso de estar com o outro motiva o casamento e determina a escolha do parceiro, pois os indivíduos esperam encontrar nesses relacionamentos uma compatibilidade afetiva, sexual e intelectual" (p. 66).

Para Norgren, Souza, Kaslow, Hammerschmidt e Sharlin (2004), a satisfação conjugal é um fenômeno complexo, no qual interferem diversas variáveis. $\mathrm{O}$ casamento transforma-se ao longo do ciclo de vida familiar e, assim, o nível de satisfação também varia com o decorrer dos anos de convívio conjugal, sendo necessário que se discutam as contemporâneas formas com que vêm se desenhando os casamentos e as uniões estáveis. O ajustamento conjugal, as formas de comunicação e as estratégias de resolução de conflitos empregadas pelo casal influenciam o desenvolvimento de padrões de cuidado dos filhos e a qualidade das relações entre os genitores e suas crianças. Por exemplo, casamentos saudáveis proporcionam mais suporte aos cônjuges do que relações maritais insatisfatórias e o apoio emocional dos pais às mães favorece o desenvolvimento saudável dos filhos (Dessen \& Braz, 2005).

A literatura, ainda segundo resgate feito por Dessen e Braz (2005), aponta inúmeros prejuízos diretos e indiretos, tanto para os cônjuges, como para seus filhos, provocados por uma relação conjugal insatisfatória. As consequências negativas das relações maritais insatisfatórias, e, possivelmente, do divórcio ou da separação do casal, incluem o aumento do risco de os cônjuges apresentarem psicopatologias, de estarem envolvidos em acidentes automobilísticos, de exposição à incidência de doenças físicas, de cometerem suicídio, homicídio ou outros atos de violência, de mortalidade em função de doenças em geral, entre outras.

Como destacado por Perlin (2006), a satisfação é um elemento fundamental em um relacionamento interpessoal. Mas, segundo revisão realizada por essa autora, existe uma verdadeira diversidade de definições do que seja a satisfação no casamento. Evocando o trabalho de outros autores, diversos termos são utilizados na literatura científica, como satisfação conjugal, satisfação matrimonial, estabilidade matrimonial, qualidade matrimonial, ajuste matrimonial, felicidade matrimonial, sucesso matrimonial, consenso matrimonial, integração matrimonial (Dela Coleta, 2006; Diniz, 1993). Essa grande diversidade na terminologia gera dificuldades para comparar resultados de estudos distintos e impõe um desafio para os pesquisadores, que têm que investigar até que ponto esses termos são sinônimos ou representam modelos distintos de compreensão da relação conjugal. Esse questionamento inspira a realização de novas revisões na literatura, como a que será aqui apresentada, focalizando o construto satisfação conjugal, como definido nas pesquisas de Dela Coleta (1989, 1992, 2006), Diniz (1993) e Perlin (2006). O que já está bem consolidado é que a literatura é uníssona ao apontar a satisfação no casamento como um fator fundamental na vida de um casal (Scorsolini-Comin \& Santos, 2008). Entretanto, é necessário delinear qual é o estatuto desse construto na produção científica, as principais tendências que têm sido contempladas e as perspectivas de pesquisas futuras.

Assim sendo, o objetivo do presente estudo é apresentar uma revisão integrativa da literatura científica acerca do tema satisfação conjugal, buscando evidenciar o perfil dos trabalhos publicados em fontes de pesquisa de impacto no contexto brasileiro, de modo a possibilitar um maior direcionamento dos estudos sobre o construto e discutir as tendências dessas publicações, bem como as perspectivas de produção na área.

\section{Método}

Trata-se de um estudo de revisão integrativa. De acordo com Beyea e Nicoll (1998), uma revisão integrativa sumariza pesquisas passadas e tira conclusões globais de um corpo de literatura de um tópico em particular. Segundo Fernandes (2000), a revisão integrativa permite a construção de uma análise ampla da literatura, contribuindo para discussões sobre métodos e resultados de pesquisa, assim como reflexões sobre a realização de futuras pesquisas. É necessário, portanto, seguir padrões de rigor e clareza na revisão e crítica, de forma que o leitor possa identificar as características reais dos estudos revisados. Seguindo os procedimentos de Ganong (1987), embora os métodos para a condução de revisões integrativas variem, existem padrões a serem seguidos. Na operacionalização dessa revisão, utilizamos as seguintes etapas: seleção da questão temática, estabelecimento dos critérios para a seleção da amostra, análise e interpretação dos resultados e apresentação da revisão.

\section{Procedimento}

As buscas nas bases foram realizadas em um único dia, em uma rede de acesso público de uma universidade pública do Estado de São Paulo. Em todas as bases de dados foi utilizado o unitermo satisfação conjugal. Após o levantamento das publicações, os resumos foram lidos e analisados segundo 
os critérios de inclusão/exclusão estabelecidos. Os trabalhos selecionados foram recuperados na íntegra e, posteriormente, analisados.

Visando assegurar uma ampla abrangência desta revisão, foram consultadas as seguintes bases: LILACS e SciELO. O levantamento compreendeu o período de 1970 a 2008. Tal abrangência de tempo objetivou traçar um perfil das publicações ao longo desses 38 anos, na tentativa de recuperar uma amostra abrangente de trabalhos produzidos a respeito do tema.

Para esta revisão, foram excluídos diversos tipos de trabalhos, tais como artigos não indexados, teses, dissertações, resenhas, livros e capítulos de livros. Esse critério se deve ao fato de que em uma das bases de dados (LILACS) há um alto registro desses trabalhos, os quais poderiam não ter passado por um processo de avaliação pelos pares. Sendo assim, a fim de buscar apenas trabalhos submetidos a um processo rigoroso de avaliação, tão necessário para garantir a qualidade da produção científica, foram selecionados apenas artigos publicados em periódicos indexados (Scorsolini-Comin \& Amorim, 2008). Foram excluídas, ainda, publicações distantes do tema, como trabalhos relacionados ao casamento entre pessoas soropositivas ou uniões homossexuais.

Como critérios de inclusão, destacam-se: artigos publicados apenas em periódicos indexados; trabalhos publicados nos idiomas inglês, espanhol e português; e, ainda, trabalhos empíricos, teóricos e de revisão acerca do tema. Os resumos condizentes com os critérios adotados foram selecionados, partindo-se daí para a busca dos trabalhos completos.

\section{Resultados e Discussão}

$\mathrm{Na}$ busca pelo unitermo satisfação conjugal nas bases SciELO e LILACS, foram encontrados 19 artigos (quatro na SciELO e 15 na LILACS). Desses, 12 foram selecionados a partir dos critérios de inclusão/exclusão e serão aqui analisados em profundidade. Dos sete trabalhos excluídos, um versava sobre suporte emocional em tratamentos de câncer de mama; dois abordavam o suporte social no contexto de enfermagem; dois tematizavam a infertilidade; um se ocupava do sofrimento feminino em relação ao trabalho; e um dizia respeito à orientação para pais de crianças com transtornos de comportamento. Destaque-se que dois artigos selecionados foram registrados nas duas bases, ou seja, analisar-se-ão em profundidade 10 trabalhos, os quais constituíram o corpus da pesquisa.

\section{Períodos e idiomas de publicação dos trabalhos}

Em relação ao ano de publicação dos trabalhos selecionados, observa-se que $70 \%$ deles se concentram nos anos 2000 , com $30 \%$ no ano de 2004 . Apenas $30 \%$ dos trabalhos foram produzidos na década de 1990. O trabalho mais antigo entre os selecionados data de 1987, o que revela a atualidade do tema. Em relação ao idioma, a maioria dos trabalhos selecionados nessas bases encontra-se disponível em português.

\section{Complexidade do tema e eixos dos trabalhos publicados}

Como será apresentado na análise crítica dos trabalhos, Wagner e Falcke (2001) destacam que a satisfação conjugal é um construto de complexa definição. Tal complexidade deve-se ao fato de que ela é composta por diferentes variáveis, desde as características de personalidade dos cônjuges e as experiências que eles trazem das suas famílias de origem até a maneira como eles constroem o relacionamento a dois. Essa complexidade motivou o desenvolvimento de um eixo de trabalhos de revisão crítica da literatura científica (Mosmann, Wagner \& Féres-Carneiro, 2006; Wagner \& Falcke, 2001). Outras pesquisas selecionadas, embora não sejam estudos de revisão, apresentam um breve mergulho na literatura científica acerca do tema, contribuindo para a caracterização das pesquisas na área (Dela Coleta, 1992; Miranda, 1987; Norgren \& cols., 2004), o que revela a necessidade de contextualização do tema investigado, uma vez que seu entendimento não é uníssono na literatura (Perlin, 2006).

Um segundo eixo de trabalhos consiste na investigação da satisfação conjugal em diferentes contextos, como em pesquisas com casais de duplo trabalho (Perlin \& Diniz, 2005), em casamentos de longa duração (Norgren \& cols., 2004), na transição da conjugalidade para a parentalidade (Magagnin \& cols., 2003) e durante a gravidez (Oriá, Alves \& Silva, 2004).

Um terceiro eixo destacado corresponde aos trabalhos que correlacionavam variáveis da satisfação conjugal a outras, tais como o locus de controle conjugal (Dela Coleta, 1992), a comunicação, a semelhança de atitudes entre os cônjuges e a percepção interpessoal (Miranda, 1987). Nesse eixo encontram-se também trabalhos que analisaram a influência de variáveis - idade, tempo de casado, autoestima, renda, escolaridade e filhos - sobre a satisfação conjugal (Miranda, 1987) e a estrutura de poder nas famílias (Rodrigues, Bystronski \& Jablonski, 1989).

$\mathrm{O}$ último eixo se refere à mensuração da satisfação conjugal. Na presente revisão, abordou-se, especificamente, os instrumentos utilizados, a partir tanto de estudos de validação quanto de aplicação de instrumentos internacionalmente reconhecidos (Magagnin \& cols., 2003; Norgren \& cols., 2004; Perlin \& Diniz, 2005; Wachelke, Andrade, Cruz, Faggiani \& Natividade, 2004). Entre os instrumentos utilizados, deve-se destacar a prevalência da Escala de Ajustamento Diádico (Dyadic Adjustment Scale - DAS), desenvolvida por Graham Spanier em 1976. A escala foi traduzida e adaptada para a população brasileira por Magagnin e cols. (2003) e é referida em boa parte dos estudos desta revisão (Magagnin \& cols., 2003; Norgren \& cols., 2004; Perlin \& Diniz, 2005).

\section{Análise crítica dos trabalhos selecionados}

A pluralidade das satisfaçães conjugais: revisão de conceitos. No primeiro trabalho selecionado, Mosmann e cols. (2006) apresentam uma revisão da literatura científica a respeito do termo qualidade conjugal. Essas autoras são consideradas grandes referências no Brasil e lideram a tradição de trabalhos publicados nessa temática. Segundo essas 
pesquisadoras assinalam em seu trabalho de revisão, apesar da ampla utilização do conceito de qualidade conjugal, identifica-se a falta de clareza conceitual acerca das variáveis que o compõem. Nesse sentido, esse artigo apresenta uma revisão da literatura na área com o objetivo de mapear o conceito de qualidade conjugal, a partir da análise de cinco principais teorias sobre o tema: Troca Social, Comportamental, Apego, Teoria da Crise e Interacionismo Simbólico.

O artigo de Mosmann e cols. (2006) destaca que a conceituação do que seria um casamento satisfatório é uma tarefa árdua no meio científico, uma vez que a análise das pesquisas internacionais da área, na última década, identifica um grande número de estudos que apontam para um alto índice de fatores que se associam à definição do conceito de satisfação conjugal. Dentre esses fatores encontram-se o bem-estar dos cônjuges e de seus filhos, as respostas fisiológicas dos cônjuges, as características sociodemográficas, a saúde física do casal, a depressão, a psicopatologia, as características de personalidade, assim como combinações dessas variáveis. As autoras apontam que, embora essas variáveis estejam correlacionadas com a qualidade da relação conjugal, há uma carência de estudos que investiguem, com profundidade, o que é a satisfação conjugal. Os trabalhos existentes não seriam orientados por uma teoria de sustentação adequada, nem possuiriam uma clara definição metodológica capaz de produzir reflexões e avanços nos estudos acerca dessa temática.

Em outro trabalho selecionado na presente revisão, Wagner e Falcke (2001) também atestam a complexidade da definição de satisfação conjugal. Tal complexidade deve-se ao fato de que ela é composta por diferentes variáveis, desde as características de personalidade dos cônjuges e as experiências que eles trazem das suas famílias de origem até a maneira como eles constroem o relacionamento a dois. $\mathrm{Na}$ revisão dessas autoras, foram elencadas, a partir dos estudos resgatados, as variáveis que se relacionam à satisfação conjugal, tais como sexo, grau de escolaridade, número de filhos e presença deles em casa, nível socioeconômico e tempo de casamento. A análise das pesquisas trazidas no artigo de Wagner e Falcke leva-nos a considerar que no conceito de satisfação conjugal estão implicadas tanto as experiências precoces do sujeito na sua família, como também os aspectos vivenciais da relação diádica atual, além das variáveis de personalidade e biodemográficas.

A partir das questões de transgeracionalidade, Wagner e Falcke (2001) destacam que a formação do casal e, consequentemente, de uma nova família, se dá por meio do encontro dos sistemas de crenças das famílias de origem dos cônjuges. Assim, quando as pessoas se casam ou passam a viver em união conjugal, acontece o encaixe entre sistemas míticos de duas estruturas familiares diferentes, formando um novo sistema baseado nos sistemas familiares de cada cônjuge. Pensando especificamente na satisfação conjugal, as autoras destacam que dificilmente um casal poderá estabelecer uma relação afetiva e sexualmente feliz se não tiver conseguido uma boa independização dos pais, consolidada nos primeiros anos de relacionamento conjugal. Salientam, entretanto, que como ninguém se separa totalmente de sua família de origem, por mais independente que seja, tanto emocional como economicamente, a atitude madura é caracterizada pela capacidade de evitar que as famílias de ambos os cônjuges entrem em conflito, preservando o bom relacionamento entre ambas. Nesse sentido, referem que é fundamental a existência de tolerância e respeito pela família do outro.

Da análise empreendida a partir desse conjunto de trabalhos (Mosmann \& cols., 2006; Wagner \& Falcke, 2001), destacamos a pluralidade de conceitos e definições relativos à satisfação conjugal. Um ponto que se coloca em aberto e que será discutido posteriormente neste trabalho se refere à mensuração desse construto. Como mensurar a satisfação conjugal se essa noção ainda se encontra em processo de definição por parte de diversos autores? Como avaliar um construto sem que haja uma voz uníssona que delimite as especificidades do mesmo? A definição de uma noção, muitas vezes, parte de um determinado contexto de investigação. Assim, é mister que se conheça de onde partem essas investigações e quais os aspectos que contribuíram para a construção de determinados conceitos. Assim, destacaremos, a seguir, alguns dos contextos de investigação da satisfação conjugal recuperados nesta revisão.

A satisfação conjugal em diferentes contextos de investigação. O estudo quantitativo de Perlin e Diniz (2005) avaliou a satisfação no casamento de homens e mulheres que optaram por relacionamentos de duplo trabalho, ou seja, casais que trabalham. Os resultados mostraram que a maioria dos participantes está satisfeita com seus relacionamentos, sendo que as mulheres apresentaram média de satisfação inferior à dos homens. Quanto à percepção do futuro do relacionamento, ficou evidente o comprometimento de homens e mulheres em investirem na manutenção do casamento. Os resultados questionam a ideia vigente de falência do casamento e da família e apontam para uma transformação das relações. Nesse trabalho, as autoras destacam que a satisfação é um elemento fundamental em um relacionamento interpessoal. Mas a pergunta: “o que é satisfação?” pode ser muito mais complexa do que se imagina, corroborando apontamentos também lançados por Mosmann e cols. (2006). Segundo revisão de Perlin e Diniz (2005), há uma diversidade de definições do que seja a satisfação no casamento. As autoras retomam uma definição extraída de outro artigo selecionado e que será aqui analisado: a satisfação é uma reação subjetivamente experienciada no casamento; é uma atitude a respeito do próprio relacionamento conjugal; é o resultado da diferença entre a percepção da realidade do casamento e as aspirações que os cônjuges têm para a relação (Dela Coleta, 1989). Perlin e Diniz (2005) destacam que outros trabalhos afirmam que a satisfação conjugal é afetada por fatores conscientes e inconscientes, ou seja, aspectos internos da psique. Ela seria afetada também por fatores do meio ambiente, tais como: o sexo, o grau de escolaridade, o número de filhos e a presença, ou não, deles dentro de casa, o nível socioeconômico e o tempo de casamento.

Outro trabalho, da autoria de Norgren e cols. (2004), investiga os casamentos de longa duração. Segundo o artigo, o relacionamento conjugal está associado à saúde e à qualidade de vida, principalmente nos anos de maturidade e velhice, embora o fato de um casamento durar não necessariamente signifique que o mesmo é satisfatório para os cônjuges. $\mathrm{O}$ estudo identifica os processos e variáveis associadas à satisfação conjugal em casamentos de longa duração, ou seja, com 
mais de 20 anos. Em cerca de metade dos casais estudados, ao menos um dos cônjuges estava satisfeito. Comparando-se casais satisfeitos e insatisfeitos foi possível identificar que a satisfação aumenta quando há proximidade, estratégias adequadas de resolução de problemas, coesão, boa habilidade de comunicação, se os cônjuges estiverem satisfeitos com seu status econômico e forem praticantes de sua crença religiosa. Para essas autoras, a satisfação conjugal é, sem dúvida, um conceito subjetivo, pois implica ter as próprias necessidades e desejos satisfeitos, assim como corresponder, em maior ou menor escala, ao que o outro espera, definindo um dar e receber recíproco e espontâneo. Relaciona-se com sensações e sentimentos de bem-estar, contentamento, companheirismo, afeição e segurança, fatores que propiciam intimidade no relacionamento, decorrendo da congruência entre as expectativas e aspirações que os cônjuges têm e a realidade vivenciada no casamento.

O estudo de Magagnin e cols. (2003) investigou longitudinalmente a transição da conjugalidade para a parentalidade quanto ao ajustamento diádico e à satisfação conjugal de casais primíparos. A questão da transição para a parentalidade também é trazida em outros estudos, como os de Menezes e Lopes (2007), que trabalham no sentido de que, entre os processos críticos que determinam as principais transições desenvolvimentais que os casais costumam passar, a transição para a parentalidade é uma das maiores mudanças por que o sistema familiar pode passar. É o momento em que os cônjuges, que antes constituíam apenas um casal, "tornam-se pais, progenitores de uma nova família. O nascimento do primogênito, em especial, é a primeira experiência de parentalidade vivida pelo casal" (Menezes \& Lopes, 2007, p. 83). Ainda, segundo Menezes e Lopes (2007), alguns estudos recentes também têm enfatizado que a transição para a parentalidade acarreta a diminuição na satisfação conjugal. O casamento, por sua vez, ao delimitar o início das famílias, também vem sendo abordado por alguns pesquisadores (e.g., Féres-Carneiro, 2003; Fonseca, 2005; Passos, 2007; Romanelli, 1995). Entretanto, a transição para o casamento e suas peculiaridades como fase inicial do desenvolvimento do casal têm sido relativamente pouco consideradas pelos teóricos que se ocupam em estudar os casais e as famílias.

Oriá, Alves e Silva (2004), trabalhando com o contexto de gravidez e a sua repercussão nos aspectos social, econômico, emocional e sexual do casal, constataram que a sexualidade na gravidez ainda envolve tabus. No grupo de 35 gestantes estudadas, destacou-se que $71 \%$ relataram situações/experiências vivenciadas, as quais as autoras salientaram como repercussões positivas ou negativas da gravidez na sexualidade dessas mulheres. Quanto às primeiras repercussões, foram referidos a melhora do relacionamento conjugal, o sentimento de feminilidade aguçada e obtenção de maior prazer sexual. Sobre as segundas, o abandono do parceiro e diminuição da atividade sexual. Assim, a partir do estudo, a gravidez pôde ser identificada como uma variável relevante que influencia na melhoria da qualidade percebida da relação conjugal, na visão da mulher.

Satisfação conjugal e outras variáveis. Dela Coleta (1992) apresenta um estudo quantitativo para mensurar a relação entre o locus de controle conjugal e a satisfação conjugal atual, passada e estimada para o futuro, a partir de instrumentos de avaliação desses construtos. Segundo o modelo apresentado por essa autora, a pessoa com predominância de locus de controle interno deverá se empenhar para resolver seus problemas conjugais e, como consequência, deverá sentir-se mais satisfeita no casamento. Esse modelo também propõe que, com o passar do tempo, as pessoas mais externas tenderiam a se tornar ainda mais externas e os mais internos tornar-se-iam mais internos, pelo fato de suas experiências de sucesso e fracasso serem reforçadas ao longo do relacionamento conjugal. Portanto, o casal, quando ambos são internos, na medida em que percebem sua capacidade de resolução de conflitos na relação conjugal, tenderiam, de modo geral, a estar mais satisfeitos com o casamento.

Em outro trabalho, Miranda (1987) analisou empiricamente a inter-relação entre satisfação conjugal e três aspectos considerados relevantes em uma relação diádica: comunicação, semelhança de atitudes e percepção interpessoal. Examinou, também, a influência de outras variáveis (idade, tempo de casado, autoestima, renda, escolaridade e filhos) sobre a satisfação conjugal. Os resultados alcançados pelo estudo de Miranda apontaram a percepção interpessoal e a autoestima como as variáveis de maior importância relativa. Teve-se, também, a oportunidade de inferir que a mulher, talvez por força de condicionantes socioculturais, coloca-se em uma posição de inferioridade na relação conjugal. De acordo com os resultados desse trabalho, pode-se identificar que a satisfação conjugal está associada ao ajustamento conjugal, à expressão de afeto, à coesão, à proximidade, capacidade de resolução de problemas e habilidade de comunicação.

Rodrigues, Bystronski e Jablonski (1989) estudaram a estrutura de poder em famílias, baseando-se nas respostas fornecidas por duas amostras de casais residentes no Rio de Janeiro. Esse trabalho constitui, essencialmente, uma réplica de um estudo conduzido por Centers e colaboradores, com casais americanos residentes em Los Angeles, no ano de 1971. Os resultados indicaram uma queda do poder decisório do marido, quando comparados com os obtidos há mais de duas décadas. A idade se correlacionou positivamente com o maior poder do marido. Satisfação conjugal e autoritarismo não mostraram associações com poder do marido, e as demais variáveis demográficas consideradas, além da idade, demonstraram associações ocasionais. Os autores notaram uma preferência por uma estrutura autonômica de poder conjugal. Esses resultados são discutidos à luz das transformações sociais decorrentes da revolução sexual, das mudanças dos papéis sexuais e da possível crise de identidade masculina.

Mensurando a satisfação conjugal. Nos estudos de Perlin e Diniz (2005), Norgren e cols. (2004) e Magagnin e cols. (2003), entre os instrumentos utilizados está a Dyadic Adjustment Scale (DAS), traduzida para a população brasileira por Magagnin e cols. (2003) e tendo sua avaliação estrutural conduzida por Hernandez (2008). Segundo Perlin e Diniz (2005), a DAS é considerada uma das medidas mais sólidas e globais da qualidade das relações interpessoais pela coerência dos itens agrupados em quatro subescalas que abarcam áreas fundamentais dos relacionamentos: satisfação, coesão, consenso e expressão de afeto. No estudo de Norgren e cols. (2004), além da DAS, foram utilizados os seguintes instrumentos: Lista de classificação de problemas, Questionário de avaliação de estratégias de resolução de 
conflitos e comunicação (Health and Stress Profile - HSP), Lista de motivos que levam o casal a permanecer junto e Lista de componentes de satisfação conjugal. No trabalho de Magagnin e cols. (2003) foi aplicada a Escala de Avaliação da Relação, desenvolvida por Hendrick, Dicke e Hendrick, em 1988.

No contexto brasileiro, Wachelke e cols. (2004) realizaram um estudo para descrever a construção e validação da Escala Fatorial de Satisfação em Relacionamento de Casal (EFS-RC), composta por fatores capazes de medir aspectos componentes da satisfação com o relacionamento. Em estudo posterior de Wachelke, Andrade, Souza e Cruz (2007), sobre a validação fatorial desse mesmo instrumento, os resultados confirmaram sua estrutura fatorial, apontando para uma relativa robustez do instrumento e dos aspectos analisados ao tratar com populações de características demográficas distintas. No entanto, os autores destacaram que alguns itens podem apresentar flutuações na representatividade do construto de satisfação com o relacionamento.

\section{Considerações Finais}

A atualidade do tema satisfação conjugal é algo acentuado na literatura, assim como a sua complexidade e a multiplicidade de vozes que são evocadas quando se discute ou se estuda a satisfação no relacionamento diádico. Tal complexidade fica evidente quando a satisfação conjugal é investigada juntamente com conceitos correlatos, como qualidade conjugal, ajustamento diádico, sucesso conjugal ou outros, conforme apontado por Mosmann e cols. (2006). A possibilidade de operacionalizar uma revisão integrativa da literatura científica só foi possível, a nosso ver, pela definição e opção metodológica por um dos termos correntes, ou seja, da satisfação conjugal, conforme utilizado por pesquisadores de referência na área (Dela Coleta, 1992; Diniz; 1993; Norgren \& cols., 2004; Perlin; 2006).

Concordamos com a percepção de Mosmann e cols. (2006) e de Wagner e Falcke (2001) de que a conceituação do que seria um casamento satisfatório é uma tarefa árdua no meio científico, uma vez que a análise das pesquisas internacionais na última década, resgatadas em ambos artigos, identifica um grande número de estudos que apontam para um alto índice de fatores que se associam à definição do conceito de satisfação conjugal. Essa multiplicidade também foi atestada no presente trabalho e pode ser justificada, segundo Wagner e Falcke, pelo fato do casamento ser um momento em que se abre a porta da família para a entrada de um novo membro, oriundo de um outro sistema familiar, que possui a sua subjetividade, individualidade e heterogeneidade. Como capturar essas nuanças no estudo da satisfação conjugal?

A delimitação do construto analisado deve ser acompanhada por uma adequada mensuração do mesmo, o que ainda não encontra suficiente respaldo na literatura nacional. Os estudos destacam a tradução de um instrumento (DAS) para nosso contexto, mas não apresentam sólidos instrumentos desenvolvidos e validados semanticamente no Brasil, à exceção de instrumentos que mensuram a satisfação em relacionamento de casal (Wachelke \& cols., 2004, 2007), o que não necessariamente corresponde à noção de satisfação conjugal, tal como apresentada neste estudo.

Assim, a preocupação de conhecer o contexto nacional e a especificidade do casamento (e da percepção que o indivíduo tem acerca do mesmo) deve permear o desenvolvimento de instrumentos de mensuração. Inevitavelmente, é preciso debruçar-se na busca de compreender o contexto do casamento em nosso país, mas não apenas em termos estatísticos ou demográficos, e o papel dessa instituição em nossa sociedade e na estrutura dos relacionamentos estabelecidos pelas pessoas. A percepção satisfatória do casamento é uma tendência na atual configuração do vínculo conjugal em nossa sociedade ou estaria diretamente ligada às especificidades de definição dos construtos de avaliação e sua consequente mensuração? Como apreender essas nuanças a partir dos estudos recuperados na presente revisão? Como não há uma única resposta para essa questão, é necessário que outros diálogos sejam fomentados a partir da aproximação com a literatura aqui apresentada.

Nesse sentido, deve-se apontar que o escopo do estudo, na mesma medida em que enfatiza a produção nacional, pode obscurecer contribuições internacionais ao estudo da satisfação conjugal, embora seja possível ter uma noção bastante precisa, ao se examinarem alguns artigos (e.g., Dessen \& Braz, 2005; Magagnin \& cols., 2003; Menezes \& Lopes, 2007; Mosmann \& cols., 2006), de como o tema vem sendo abordado e difundido em nosso contexto. Por esse movimento, alguns questionamentos abrem possibilidades de interlocução a serem investigadas por estudos futuros: quais as especificidades culturais de nosso contexto que deveriam estar contempladas nos estudos da satisfação conjugal? Como o contexto vem sendo apreendido na perspectiva desses instrumentos de mensuração? Qual o espaço que tem sido ocupado por investigações específicas nessa temática em nosso país, que tenham a satisfação conjugal como objeto de estudo e não apenas como um construto tangencial?

Desse modo, a partir dos dados apresentados nesta revisão integrativa, destaca-se a premência de desenvolvimento de outros trabalhos, que investiguem não apenas a satisfação conjugal em diferentes contextos e na relação com outras variáveis, mas a partir de seus instrumentos de mensuração, uma vez que a avaliação das dimensões que constituem esse construto só é possível a partir de instrumentos cientificamente validados, que ampliem as possibilidades de aplicação em contextos diferenciados, como apontado por Norgren e cols. (2004) e Scorsolini-Comin e Santos (2008). Retomando as reflexões de Perlin (2006), os estudos sobre satisfação devem estar pautados em critérios científicos rígidos, a fim de que possam agregar conhecimentos aos estudos já produzidos. Nessa direção, a relevância da revisão integrativa repousa em permitir sistematizar as produções veiculadas na contemporaneidade, dando visibilidade para o conhecimento produzido e, ao mesmo tempo, apontando as áreas lacunares, a fim de contribuir com o delineamento de novas investigações e novos saberes, na medida da urgência da demanda da ciência psicológica. 


\section{Referências}

Beyea, S. C., \& Nicoll, L.H. (1998). Writing in integrative review. AORN Journal, 67, 877-880.

Costa, M. E. (2005). À procura da intimidade. Porto: Edições Asa.

Dela Coleta, M. F. (1989). A medida da satisfação conjugal: adaptação de uma escala. Psico, 18, 90-112.

Dela Coleta, M. F. (1992). Locus de controle e satisfação conjugal. Psicologia Teoria e Pesquisa, 8, 243-252.

Dela Coleta, M. F. (2006). Atribuição de causalidade, locus de controle e relações conjugais. Em J. A. Dela Coleta \& M. F. Dela Coleta (Orgs.). Atribuição de causalidade: teoria, pesquisa e aplicações (pp. 199-244). Taubaté: Cabral.

Dessen, M. A., \& Braz, M. P. (2005). Rede social de apoio durante transições familiares decorrentes do nascimento de filhos. Psicologia: Teoria e Pesquisa 16, 221-231.

Dias, M. (2000). A construção do casal: Um estudo sobre as relações conjugais contemporâneas. Tese de Doutorado, Pontifícia Universidade Católica, Rio de Janeiro.

Diniz, G. (1993). The interaction between work. Gender-roles and marriage-family dilemmas in dual career and dual worker couples. Tese de Doutorado, United States International University, San Diego.

Féres-Carneiro, T. (1998). Casamento contemporâneo: o difícil convívio da individualidade com a conjugalidade. Psicologia: Reflexão e Crítica, 11, 379-394.

Féres-Carneiro, T. (2003). Separação: o doloroso processo de dissolução da conjugalidade. Estudos de Psicologia, 8, 367-374.

Fernandes, L. M. (2000). Úlcera de pressão em pacientes críticos hospitalizados: uma revisão integrativa da literatura. Dissertação de mestrado, Universidade de São Paulo, Ribeirão Preto.

Fonseca, C. (2005). Concepções de família e práticas de intervenção: uma contribuição antropológica. Saúde e Sociedade, 14, 30-59.

Ganong, L. H. (1987). Integrative reviews of nursing research. Research in Nursing \& Health, 1, 1-11.

Hernandez, J. A. E. (2008). Avaliação estrutural da escala de ajustamento diádico. Psicologia em Estudo, 13, 593-601.

Instituto Brasileiro de Geografia e Estatística - IBGE (2007). Comunicação social de 06 de dezembro de 2007. Retirado em 23/072008, de http://www.ibge.gov.br/home/presidencia/noticias/ noticia_impressao.php?id_noticia $=1046$.

Lipovetsky, G. (2007). A felicidade paradoxal: ensaios sobre a sociedade de hiperconsumo (M. L. Machado, Trad.). São Paulo: Companhia das Letras. (Trabalho original publicado em 2006)

Machado, L. M. (2007). Satisfação e insatisfação no casamento: Os dois lados de uma mesma moeda? Dissertação de Mestrado, Universidade Federal de Uberlândia, Uberlândia.

Magagnin, C., Kõrbes, J. M., Hernandez, J. A. E., Cafruni, S., Rodrigues, M. T., \& Zarpelon, M. (2003). Da conjugalidade à parentalidade: gravidez, ajustamento e satisfação conjugal. Aletheia, 17/18, 41-52.

Menezes, C. C., \& Lopes, R. C. S. (2007). Relação conjugal na transição para a parentalidade: gestação até dezoito meses do bebê. PsicoUSF, 12, 83-93.
Miranda, E. S. (1987). Satisfação conjugal e aspectos relacionados: a influência da comunicação, da semelhança de atitudes e da percepção interpessoal. Arquivos Brasileiros de Psicologia, 39, 96-107.

Mosmann, C., Wagner, A., \& Féres-Carneiro, T. (2006). Qualidade conjugal: mapeando conceitos. Paideia, 16, 315-325.

Norgren, M. B. P., Souza, R. M., Kaslow, F., Hammerschmidt, H., \& Sharlin, S. A. (2004). Satisfação conjugal em casamentos de longa duração: uma construção possível. Estudos de Psicologia, (Natal), 9, 575-584.

Oriá, M. O. B., Alves, M. D. S., \& Silva, R. M. (2004). Repercussões da gravidez na sexualidade feminina. Revista Enfermagem UERJ, 12, 160-165.

Passos, M. C. (2007). A constituição dos laços na família em tempos de individualismo. Mental, 5, 1-9.

Perlin, G. D. B. (2006). Casamentos contemporâneos: um estudo sobre os impactos da interação família-trabalho na satisfação conjugal. Tese de Doutorado, Universidade de Brasília, Brasília.

Perlin, G., \& Diniz, G. (2005). Casais que trabalham e são felizes: mito ou realidade? Psicologia Clínica, 17, 15-29.

Rodrigues, A., Bystronski, B., \& Jablonski, B. (1989). A estrutura do poder conjugal: uma análise de duas culturas em duas épocas. Arquivos Brasileiros de Psicologia, 41, 13-24.

Romanelli, G. (1995). Autoridade e poder na família. Em M. C. B. Carvalho (Org.), A família contemporânea em debate (pp. 73-88). São Paulo: EDUC/Cortez.

Scorsolini-Comin, F., \& Amorim, K. S. (2008). Corporeidade: uma revisão crítica da literatura científica. Psicologia em Revista, 14, 189-214.

Scorsolini-Comin, F., \& Santos, M. A. (2008). Casamento na medida: uma revisão integrativa de conceitos e instrumentos de mensuração da satisfação conjugal. Em S. R. Pasian, E. T. K. Okino, S. R. Loureiro \& F. L. Osório (Org.), Avaliação de personalidade: técnicas e contextos diversos (pp. 55-67) Ribeirão Preto: Vetor.

Spanier, G. B. (1976). Measuring dyadic adjustment: New scales for assessing quality of marriage and similar dyads. Journal of Marriage and the Family, 38, 15-28.

Wachelke, J. F. R., Andrade, A. L. de, Cruz, R. M., Faggiani, R. B., \& Natividade, J. C. (2004). Medida da satisfação em relacionamento de casal. Psico-USF, 9, 11-18.

Wachelke, J. F. R., Andrade, A. L., Souza, A. M., \& Cruz, R. M. (2007). Estudo complementar da validade fatorial da escala fatorial de satisfação em relacionamento e predição de satisfação global com a relação. Psico-USF, 12, 221-225.

Wagner, A., \& Falcke, D. (2001). Satisfação conjugal e transgeracionalidade: uma revisão teórica sobre o tema. Psicologia Clínica, 13, 1-15. 